\title{
Lilia Schwarcz e a persistência do nacionalismo metodológico nas interpretações do Brasil
}

SCHWARCZ, Lilia Moritz. Sobre o autoritarismo brasileiro. São Paulo: Companhia das Letras, 2019. 273p.

\section{Marcos Abraão Ribeiro*}

\section{Resumo}

Esta resenha apresenta uma análise crítica do livro Sobre o autoritarismo brasileiro, da antropóloga e historiadora Lilia Schwarcz, que procura realizar uma interpretação multidimensional do autoritarismo nacional. Através da apresentação dos argumentos principais presentes no livro, defendo que a autora constrói uma interpretação que não rompe com as tradicionais imagens do Brasil, reproduz uma perspectiva idealizada do sistema democrático e segue o nacionalismo metodológico, que fazem com que sua interpretação enfatize as supostas particularidades do caso brasileiro. Dessa forma, seu trabalho contribui para que continuemos em posição subordinada dentro da geopolítica do conhecimento na modernidade global.

Palavras-chave: autoritarismo, nacionalismo metodológico, geopolítica do conhecimento.

* Instituto Federal de Educação, Ciência e Tecnologia Fluminense (IFF), Campos dos Goytacazes, RJ, Brasil. 


\section{Lilia Schwarcz and the persistence of methodological nationalism in interpretations of Brazil}

\section{Abstract}

This review presents a critical analysis of the book Sobre o autoritarismo brasileiro (On Brazilian authoritarianism), by anthropologist and historian Lilia Schwarcz, which seeks to make a multidimensional interpretation of national authoritarianism. By presenting the main arguments in the book, I argue that the author constructs an interpretation that does not break with traditional images of Brazil, but rather reproduces an idealized perspective of the democratic system, following the methodological nationalism, what leads her to emphasize some supposed particularities of the Brazilian case. Thus, Schwarcz's work contributes to crystallize the subordinate position of Brazil within the geopolitics of knowledge in global modernity.

Keywords: authoritarianism, methodological nationalism, geopolitics of knowledge.

o revisitarmos as tradicionais interpretações do pensamento social e
político brasileiro, observamos que o autoritarismo e suas causas são
questões centrais, pois através delas são investigadas nossas raízes desde a colonização portuguesa ou além, quando a busca pelos males brasileiros vai até a península ibérica. Como forma de sustentar a centralidade do tema do autoritarismo, cito as obras clássicas de Tavares Bastos (1976), Raymundo Faoro (2008), Antonio Paim (1998), Simon Schwartzman (1988), Sérgio Buarque de Holanda (2010) e Roberto DaMatta (1978), apenas para ficarmos com autores da tradição culturalista de interpretação do Brasil, à qual o trabalho resenhado está filiado.

Essas leituras procuram interpretar as causas do nosso atraso, responsável por fazer com que constituíssemos uma ordem autoritária marcada pelo domínio privatista sobre o Estado. Por conseguinte, formamos uma sociedade marcada por dilemas como o arbítrio, a desigualdade e, o que é mais importante, por uma realidade essencialmente diferente das democracias 
que existiriam nos países centrais. Através das interpretações supracitadas seria possível compreender por que não formamos uma autêntica ordem republicana, com Estado racional-legal, divisão entre público e privado, racionalização e secularização - precisamente, porque constituímos uma ordem essencialmente diferente das democracias ocidentais. A resposta para tal hiato civilizacional seria dada pela herança ibérica, responsável por perpetuar uma cultura privatista, autoritária, desigual e excludente. Teríamos constituído, portanto, uma sociedade baseada no princípio da singularidade (Tavolaro, 2014). Não à toa, as leituras que buscam compreender a gênese e os mecanismos de reprodução do autoritarismo brasileiro foram formuladas em momentos dramáticos da história nacional. No caso de Tavares Bastos (1976), sua intepretação sobre Os males do presente e as esperanças do futuro foi estabelecida na década de $1870^{1}$, na qual as contradições do Império estavam sendo colocadas em xeque. O autor elaborou ideias que defendiam a constituição de uma monarquia federalista como salvação para o regime monárquico (Tavares Bastos, 1975). A interpretação de Sérgio Buarque de Holanda (2010) foi realizada alguns anos após a Revolução de 1930, quando nossos intelectuais se debruçavam sobre os desafios para modernizar o Brasil e conectá-lo de forma plena à civilização ocidental. Roberto DaMatta (1978) tinha como objetivo compreender o autoritarismo da sociedade brasileira que, por sua vez, se desdobrava em autoritarismo institucional. Já as intepretações de Raymundo Faoro (2008) - no caso específico, a segunda edição de Os donos do poder -, Antonio Paim (1998) e Simon Schwartzman (1988) tinham como objetivo fornecer explicações para o golpe de 1964 e para o consequente autoritarismo vigente no país na década de 1970. Apesar das diferenças, essas interpretações têm como núcleo comum interpretar o presente pelo passado, através de uma leitura do Brasil que une particularismo, idealização das sociedades do Atlântico

${ }^{1} \mathrm{O}$ livro Os males do presente e as esperanças do futuro foi publicado em 1861 - sob o pseudônimo de Um Excêntrico -, mas o seu livro mais importante, A província foi publicado em 1870, quando o publicista alagoano apresentou uma análise sistemática e um programa de descentralização nos moldes do federalismo americano, como medida para reformar o sistema monárquico brasileiro e salvá-lo. 
Norte e nacionalismo metodológico. Como procuro sustentar nesta resenha, o trabalho de Schwarcz também é baseado nos elementos que estruturam as leituras culturalistas clássicas sobre o autoritarismo brasileiro.

Depois do término da ditadura civil-militar (1964-1985), o interesse pelo tema do autoritarismo cedeu lugar para questões como democracia, cidadania, movimentos sociais, sociedade civil, participação - enfim, a atenção voltou-se para o processo de redemocratização do Brasil, com todas as expectativas que sua retomada trazia para diversos setores da sociedade. O tema do autoritarismo, todavia, voltou à ordem do dia com a intrincada conjuntura política enfrentada pelo Brasil contemporâneo, sobretudo depois do golpe parlamentar de 2016 (Santos, 2017), que retirou a presidente Dilma Rousseff (PT), eleita democraticamente em outubro de 2014. Como demonstração da centralidade do tema, existem importantes trabalhos como os de Santos (2017), Souza (2016), Domingues (2017), Miguel (2019) e Schwarcz (2019), este último, objeto de análise nesta resenha.

Analisarei o ambicioso trabalho de Lilia Schwarcz com o objetivo de defender que a autora constrói uma interpretação do Brasil que não consegue romper com os particularismos nacionais, com o consequente nacionalismo metodológico e com a idealização do sistema democrático que existiria nos países centrais, aspectos presentes nas tradições estatista e privatista do pensamento social e político brasileiro, sintetizadas pelo seu trabalho. Antes, porém, apresentarei os argumentos principais presentes no livro e, ao final, farei uma apreciação crítica sobre o trabalho da autora que procura compreender o Brasil em mais uma conjuntura dramática de nossa vida política.

O livro de Lilia Schwarcz ganhou ainda mais relevância e interesse com a eleição do primeiro presidente reconhecidamente de extrema direita, o capitão reformado do Exército e ex-deputado federal Jair Messias 
Bolsonaro ${ }^{2}$ (sem partido). Será o governo Bolsonaro a confirmação de nossa herança autoritária ou a demarcação da necessidade de darmos um passo além de nossas tradicionais interpretações? A antropóloga e historiadora constrói sua explicação no sentido de confirmar os diagnósticos sobre a nossa herança arbitrária e do consequente descaminho que estabelecemos em relação à democracia.

O trabalho é dividido em oito capítulos, cujos temas trazem uma visão abrangente e multidimensional sobre o autoritarismo brasileiro. No primeiro capítulo, a autora estrutura as bases para as interpretações presentes nos demais capítulos do livro, ao sustentar que a herança da escravidão é decisiva para as leituras da conjuntura atual realizadas com dados sobre a violência e a desigualdade. O capitulo traz, assim, a sociogênese do autoritarismo brasileiro. A autora defende que a naturalização da desigualdade constituída no período escravista foi fundamental para que reproduzíssemos, na sociedade de classes, o racismo, a ideologia de privilégios e o autoritarismo como gramática estruturante de nossas relações sociais e político-institucionais. É através da ênfase na escravidão que Schwarcz sustentará que o Brasil moderno foi constituído como uma sociedade profundamente desigual, marcada pelo autoritarismo nas dimensões societal e institucional: "[a] escravidão nos legou uma sociedade autoritária, a qual tratamos de reproduzir em termos modernos" (p. 35). A partir da ênfase na escravidão, a autora constrói sua interpretação, realizando uma síntese das tradições estatista e privatista do autoritarismo nacional. Este capítulo também é central para o livro resenhado, porque nele a autora apresenta a dimensão normativa, que é a defesa da democracia e a luta contra o autoritarismo, analisadas como realidades essencialmente distintas.

No segundo capítulo, Schwarcz expõe a dimensão propriamente política do autoritarismo, através de uma abordagem sociogenética do

${ }^{2}$ Enquanto escrevia esta resenha, o presidente Jair Bolsonaro anunciava a sua saída do Partido Social Liberal (PSL), para fundar sua própria agremiação política, a Aliança Pelo Brasil (APB). Essa saída ocorreu por desentendimentos com o presidente da legenda, o deputado federal pelo estado de Pernambuco, Luciano Bivar. Especificamente, o ponto central do desentendimento foi sobre o controle do fundo partidário. 
mandonismo, ou seja, da dominação particularista e autoritária. A autora retoma a sociedade colonial para defender que constituímos, desde aquele período, uma sociedade patriarcal, pautada pelo arbítrio e o domínio elitista sobre os setores subalternos. A partir da ênfase nos elementos políticos da (má) formação nacional durante o período escravista, Schwarcz sustenta que estabelecemos uma república marcada pela falta, uma vez que o elemento decisivo a conformá-la foi o privatismo, que poderia ser identificado através de tradicionais gramáticas políticas como mandonismo, coronelismo, clientelismo e populismo. Mesmo dando ênfase decisiva ao passado, a autora salienta que não está construindo uma análise pautada por uma continuação mecânica da história brasileira, uma vez que traz dados sobre as oligarquias existentes no sistema político brasileiro que, apesar das mudanças sociais ocorridas, continuariam a demonstrar a força de nossa raiz autoritária.

No terceiro capítulo, a autora aborda o conceito de patrimonialismo como a dimensão política central do autoritarismo brasileiro. Em consonância com a tradição culturalista do pensamento social e político, apresentada na introdução desta resenha, a autora defende que herdamos da colonização portuguesa a dominação tradicional, privatista e arbitrária sobre o Estado, que é elemento decisivo para defender que não nos tornamos uma autêntica república, que temos uma cidadania precária e um Estado a serviço apenas dos interesses das elites que o controlam. Ou seja, o recurso ao passado forneceria condições para a autora defender o caráter inconcluso de nossa democracia que, em sua dimensão especificamente política, teria no patrimonialismo seu principal entrave.

Para sustentar a força do patrimonialismo brasileiro, Schwarcz demonstra a origem oligárquica do parlamento nacional, a eleição de parentes de políticos pelos partidos, a concessão de emendas parlamentares e os últimos trinta anos da política brasileira. Nesse sentido, Schwarcz defende a atualidade do conceito de patrimonialismo para interpretar os dilemas da inconclusa democracia brasileira: “(...) o certo é que o conceito continua operante no Brasil, onde a prática política é ainda muita afeita à mistura 
entre afetos políticos e privados" (p. 68). O domínio dos interesses privados poderia ser observado através da força do personalismo político que se estrutura através de conchavo, apadrinhamento, mandonismo, decisivos para que a regra pública seja sobrepujada (p. 68). A história brasileira, portanto, teria sido marcada pelo patrimonialismo, responsável por consolidar, de maneira personalista e autoritária, a forma como lidamos com o Estado.

No quarto capítulo, a autora discute a corrupção, cuja raiz está no patrimonialismo desenvolvido desde o período colonial. Durante a Colônia, a corrupção teria sido reproduzida por causa da falta do Estado, associada à escravidão e à ausência de moralidade. Para sustentar o caráter central da corrupção, Schwarcz aborda fatos políticos importantes da história brasileira como a compra de títulos de nobreza durante o Império, a política dos governadores, as fraudes eleitorais na Primeira República, a ditadura civil-militar, o governo Collor e o mensalão do governo Lula (PT). Esses acontecimentos demonstrariam como a corrupção é elemento enraizado, ou seja, como temos uma tradição de corrupção, pois ela seria, entre nós, uma máquina de governar (p. 117). Além de apontar a centralidade da corrupção para a vida nacional, Schwarcz aposta na democracia como caminho necessário para combatê-la: "nada pode provar que ela (corrupção) faz parte do caráter nacional e que, portanto, não há de ser extirpada com o aperfeiçoamento da democracia" (p. 123).

No quinto capítulo, a autora apresenta a desigualdade como outra dimensão central do autoritarismo brasileiro. Schwarcz refere-se ao regime escravista para reforçar que o Brasil é formado pela linguagem da escravidão. Mesmo com o recurso ao passado, a autora apresenta dados atuais sobre concentração de renda entre os mais ricos, pobreza extrema, tributação regressiva, desigualdade no acesso à educação de qualidade, taxas de analfabetismo e abandono escolar. Além da exposição de relevantes dados, neste capítulo, a dimensão normativa do trabalho de Schwarcz aparece com mais ênfase quando comparada aos capítulos anteriores, através da defesa de um projeto nacional de educação baseado em escolas de qualidade e democráticas. 
No sexto capítulo, a autora segue a apresentação de dados atuais, neste caso sobre a violência no Brasil. Mesmo com a exposição de informações sobre o número de homicídios, especialmente o de jovens pobres, a autora liga o dilema da violência ao período escravista apresentado no primeiro capítulo, pois constituímos, desde aquele período, um padrão violento de relações sociais e institucionais que se perpetuou ao longo de nossa história. Ao mesmo tempo, a autora reforça o lado normativo de sua interpretação, ao criticar as ações do governo Bolsonaro, como a desarticulação da Funai, bem como as saídas autoritárias e violentas representadas pelas ações do atual governo brasileiro. Neste capítulo, a autora realiza uma crítica aberta ao governo de extrema direita por suas ações para apagar as minorias. Ou seja, os elementos apresentados nos capítulos anteriores e neste, em particular, dariam as condições para construir uma explicação para o atual governo brasileiro.

No sétimo capítulo, Schwarcz aborda as questões de raça e gênero para defender que negros e mulheres sofrem as consequências do racismo e do patriarcalismo, respectivamente, além de viverem em situação de vulnerabilidade social. Dessa forma, a autora reforça o peso da escravidão, da misoginia e do autoritarismo como dilemas centrais enfrentados por negros e mulheres no Brasil contemporâneo. Seguindo a postura normativa adotada nos dois capítulos anteriores, Schwarcz defende as políticas de ações afirmativas para lutar contra o racismo e suas consequências, a necessidade de políticas públicas para enfrentar a violência contra a mulher e o direito à diversidade, tão ameaçados pelo governo Bolsonaro.

No oitavo capítulo, o tema da intolerância é discutido, a partir da crítica ao mito da brasilidade, que representa o brasileiro como passivo e tolerante em suas relações sociais. Através do recurso ao passado, abordado de forma sistemática nos primeiros capítulos, seria possível defender que constituímos uma estrutura social marcada pela intolerância e, consequentemente, por uma razão essencialmente distinta da democracia, representada pela ausência de uma cultura política democrática. Ao mesmo tempo, existe a defesa da relação antinômica entre autoritarismo e democracia, que seria 
o télos a ser alcançado. Nesse sentido, Schwarcz defende a necessidade de construção de um projeto de nação inclusivo e igualitário, ou seja, da formulação de uma concepção que possa instituir a autêntica democracia no Brasil.

Na conclusão do livro, Lilia Schwarcz sustenta que repetimos os vícios de origem durante nossa história, representados pela concentração de renda e a desigualdade, o racismo estrutural, a violência e o patrimonialismo (p. 224). Esses dilemas demonstrariam como a república brasileira descumpre a regra democrática, a qual deveria ser o alfa e o ômega dessa forma de organização do poder. Devido ao déficit republicano, repetimos o autoritarismo, representado, por exemplo, pelo populismo autoritário do atual governo brasileiro. Ao mesmo tempo, a autora aponta caminhos para enfrentar o autoritarismo, como um pacto constitucional e a resistência contra os retrocessos civilizatórios (p. 237).

O livro de Lilia Schwarcz tem, seguramente, grande relevância do ponto de vista político, uma vez que pode ser lido como uma defesa ética do sistema democrático, da pluralidade, da cidadania e da justiça social. Considero esta a dimensão mais relevante do seu trabalho, pois expõe uma série de dados importantes que nos mostram a necessidade de combater mazelas como a corrupção, a desigualdade, o racismo e a intolerância. Seu posicionamento ético em relação a dilemas tão difíceis de um dos países mais desiguais do mundo faz com que o trabalho tenha grande valor para o campo progressista em um momento marcado por retrocessos civilizatórios, demarcados pela própria autora, que colocam em risco as conquistas das últimas décadas no Brasil.

Do ponto de vista acadêmico, o trabalho possui importante relevância porque apresenta uma interpretação abrangente do autoritarismo existente no Brasil, pois analisa as raízes sociais e político-institucionais do fenômeno entre nós. Além disso, a autora aborda temas que não estão presentes nas interpretações clássicas apresentadas na resenha, como gênero e intolerância. Nesse sentido, Schwarcz constrói uma visão plural do autoritarismo nacional, uma vez que supera a perspectiva puramente institucionalista de autores 
clássicos como Tavares Bastos, Raymundo Faoro, Simon Schwartzman e Antonio Paim, bem como as análises propriamente sociológicas que enfocam a sociedade como causa do autoritarismo, como Sérgio Buarque de Holanda e Roberto DaMatta. O trabalho, portanto, realiza uma síntese das tradições estatista e privatista de interpretação do Brasil e aprofunda a explicação das causas do autoritarismo.

Apesar da síntese analítica e dos novos elementos trazidos à explicação, a autora segue a perspectiva culturalista, particularista e essencialista que analisa o autoritarismo como fenômeno estritamente brasileiro, ou seja, que demarca o fenômeno como fruto exclusivo do processo histórico nacional ${ }^{3}$. Schwarcz, portanto, reitera as clássicas imagens culturalistas sobre o Brasil. Nesse sentido, gostaria de pontuar com mais vagar as principais limitações do trabalho da antropóloga e historiadora.

Começo pelo peso dado à escravidão. Apesar de afirmar que não construiu uma leitura mecânica da mudança social, Schwarcz tem no passado o elemento decisivo para interpretar o autoritarismo brasileiro, pois defende que o Brasil teria constituído uma ordem republicana marcada pela incompletude, falta e desvio em relação às sociedades efetivamente democráticas. Ora, nesse sentido, o trabalho resenhado segue as tradicionais leituras do autoritarismo existentes no pensamento social e político brasileiro, pois tanto a tradição estatista quanto a tradição privatista, cada qual ao seu modo, vão colocar no passado colonial, escravista e tradicionalista a causa central do autoritarismo brasileiro.

Precisamente, não existem, na interpretação de Schwarcz, conflitos e questões criadas pela conjuntura atual, ou seja, dilemas modernos e que não se restringem à realidade brasileira ${ }^{4}$. Da mesma forma, inexiste uma

\footnotetext{
3É importante assinalar que Schwarcz demarca, pontualmente, as experiências autoritárias contemporâneas em países como Hungria, Polônia, Estados Unidos, Rússia, Itália e Israel. Contudo, a autora procura apontar os elementos autoritários que seriam particulares à realidade brasileira, pois resultantes do seu processo histórico, o que justifica minha abordagem crítica nesta resenha.

${ }^{4}$ Essa leitura moderna e em perspectiva global pode ser encontrada no trabalho de Domingues (2013a), que defende que construímos uma nova história a partir de 2013, e que esta tem de ser pensada a partir de uma perspectiva dialética e global.
} 
leitura rigorosa do conceito de patrimonialismo a partir da sociologia da dominação weberiana, pois a autora o utiliza de forma classificatória e próxima à leitura do senso comum, e não como tipo ideal e conceito usado em perspectiva histórica para analisar a dominação tradicional no Brasil ${ }^{5}$. Falta rigor na utilização daquele que é o principal conceito utilizado para entender os dilemas políticos no Brasil contemporâneo.

A crítica ao mito nacional é de grande valor, pois explicita o conteúdo conservador e mesmo reacionário presente nele. No entanto, ela não é sistematizada pelo trabalho da antropóloga e historiadora, mesmo sendo uma dimensão central. Sobre este aspecto, vale ressaltar uma importante lacuna no livro de Schwarcz, que é a ausência do trabalho de Marilena Chauí (2013), que analisa as representações ideológicas do autoritarismo no Brasil. Acredito que a referência ao trabalho da autora daria mais abrangência e sustentação ao argumento de Schwarcz sobre o mito nacional e seus desdobramentos políticos.

Em minha visão, o principal problema da interpretação de Lilia Schwarcz está na defesa de um autoritarismo brasileiro. Defendo este argumento por dois motivos. O primeiro é o nacionalismo metodológico, que coloca o problema como estritamente nacional, deixando como pressuposto a ideia de que o fenômeno nos moldes apresentados no livro não possa existir também nos países centrais, mesmo que em intensidade menor. Precisamente, o livro é estruturado por uma perspectiva culturalista que essencializa o caso brasileiro, a qual, como vimos, está presente nas tradições estatista e privatista sintetizadas por Schwarcz.

O nacionalismo metodológico, presente no livro, delimita o tema do autoritarismo às fronteiras do Estado nacional. Nesse sentido, faz com que

\footnotetext{
${ }^{5}$ Uma leitura rigorosa sobre a presença do conceito de patrimonialismo na obra de Max Weber está presente no trabalho de Carlos Sell (2016). Sell defende que, partindo-se dos trabalhos weberianos sobre o tema, as leituras levadas a cabo no Brasil não se sustentam, pois as interpretações brasileiras ignoram que o tema do patrimonialismo, em Weber, é baseado em dois modelos separados pela Primeira Guerra Mundial. Nos primeiros escritos de Weber, o patrimonialismo seria uma derivação do patriarcalismo. Na produção do pós-guerra, Weber defende que a dominação patrimonial possui uma relação de descontinuidade em relação à dominação patriarcal. No caso brasileiro, existe a mistura dos dois modelos sem a devida atenção às descontinuidades (Sell, 2016).
} 
sua interpretação tenha limites cognitivos, teóricos, políticos e empíricos, uma vez que ignora as formas globais de produção e de reprodução ${ }^{\mathbf{6}}$ (Maciel, 2013, p. 86). Caso o nacionalismo metodológico não fosse dimensão central do livro resenhado, a autora teria condições de contribuir para demarcar as insuficiências das tradicionais interpretações do autoritarismo brasileiro, bem como contribuiria para a formulação de uma agenda de pesquisa sobre o autoritarismo e suas formas de reprodução no mundo globalizado. Minha crítica, obviamente, não implica negar a existência do autoritarismo no Brasil, mas sim questionar a persistência em interpretá-lo como fenômeno circunscrito às fronteiras nacionais. Dessa forma, não conseguimos condições analíticas para demarcá-lo a partir de uma perspectiva que interprete o país inserindo-o em uma lógica dialética e global.

O outro ponto, e que considero o mais problemático, é a idealização do sistema democrático, também presente nas tradições sintetizadas pelo trabalho resenhado. A idealização ocorre porque Schwarcz considera o autoritarismo como antônimo da democracia, ou seja, o primeiro seria estruturado por uma razão essencialmente diversa do regime democrático. O autoritarismo seria fruto do processo histórico representado pela junção entre colonização ibérica e escravidão, responsáveis por impedir que a democracia se constituísse de forma plena no Brasil moderno. A autora reproduz uma perspectiva teleológica da democracia, pois esta seria o regime político no qual as dimensões privada e pública estariam plenamente separadas, a república seria autêntica e os interesses presentes na sociedade seriam atendidos de forma transparente, impessoal e justa. Ou seja, seria o regime em que não haveria o peso decisivo das relações pessoais que, por

\footnotetext{
${ }^{6}$ Maciel (2013) faz uma importante exposição da questão do nacionalismo metodológico como formulado pelo sociólogo alemão Ulrich Beck, que critica as interpretações sobre a desigualdade circunscritas às fronteiras nacionais. Sobre a questão, o autor argumenta: "[d] ito de outro modo, o nacionalismo metodológico é a percepção da desigualdade social como uma questão estritamente nacional, o que ignora suas formas de produção e reprodução. A fraqueza teórica desta perspectiva consiste em reduzir a conformação das desigualdades sociais de toda natureza (entre classes, grupos, indivíduos, gêneros, regiões etc.) ao âmbito das sociedades nacionais. Este movimento teórico e político, com seu enfoque exclusivo nos Estados nacionais como objeto de estudo, torna opacas na análise as forças supranacionais que conformam as desigualdades sociais" (Maciel, 2013, p. 86).
} 
sua vez, representam o jeitinho brasileiro, o autoritarismo e a consequente singularidade nacional. Dessa forma, não poderiam existir saídas autoritárias dentro da democracia.

Assim como as leituras culturalistas clássicas sintetizadas por Schwarcz, o trabalho não nos fornece condições de compreender, por exemplo, o fenômeno global da desdemocratização e da complexa e problemática relação entre democracia política e desigualdade, que são dilemas centrais do mundo contemporâneo (Miguel, 2019). Em decorrência, continuamos a ter um regime inferior e incompleto em relação aos países centrais. Ao contrário do livro por mim resenhado, temos, por exemplo, o trabalho de Santos (2017), que defende que o golpe parlamentar de 2016 é elemento intrínseco ao sistema democrático, e que o Brasil expressaria o futuro deste sistema em sua relação problemática com o capitalismo. $\mathrm{O}$ trabalho utiliza o Brasil para defender que o autoritarismo pode e deve ser pensado como elemento intrínseco ao sistema democrático. O ponto central, e que falta ao trabalho de Schwarcz, é a construção de uma interpretação que nos possibilite a comparação com os países centrais sem a presença de juízos de valor que nos inferiorizam permanentemente.

Quando Schwarcz defende a necessidade de compreender o autoritarismo brasileiro, ou seja, o dilema central para a superação das estruturas tradicionais herdadas da colonização ${ }^{7}$ (Lynch, 2016), a autora internaliza o atraso e a condição de subalternidade frente aos países centrais, que, por sua vez, seriam aqueles onde a teoria com validade universal seria produzida (Lynch, 2013). Como consequência, teríamos como missão produzir pensamento para analisar a realidade nacional (Lynch, 2013), o que é efetivado de forma exemplar pelo livro de Schwarcz.

O trabalho resenhado, portanto, não contribui para que possamos produzir teoria a partir da periferia, e para que consigamos estabelecer

\footnotetext{
${ }^{7}$ Christian Lynch (2016) argumenta que o pensamento político brasileiro possui um estilo de redação próprio que o leva a enfocar a realidade nacional, que seria atrasada em relação à modernidade cêntrica: "[o] resultado foi um 'estilo periférico' de redação e argumentação que contrasta singularmente com aquele, 'cosmopolita' ou 'universal', que caracteriza as obras canônicas da teoria política europeia" (Lynch, 2016, p. 83).
} 
outra geopolítica do conhecimento ${ }^{8}$ que nos dê condições de construir intepretações que possam demonstrar o que possuímos de efetivamente nosso e, consequentemente, o que temos em comum com os países centrais ${ }^{9}$. Em última instância, o trabalho nos impossibilita pensar o mundo a partir da periferia (Brandão, 2007). Portanto, para nos afastarmos da condição estrutural de subalternidade na geopolítica do conhecimento, devemos estudar o fenômeno do autoritarismo no Brasil, e não a suposta existência de um autoritarismo essencialmente brasileiro.

O esforço louvável de Schwarcz para pensar de forma abrangente e multidimensional um tema central do Brasil contemporâneo nos mostra a necessidade de os intelectuais progressistas se posicionarem de forma pública e ética contra o autoritarismo e os retrocessos civilizatórios que nos assolam. Da mesma forma, mesmo que de maneira não intencional, o trabalho de Schwarcz nos mostra a necessidade de a sociologia brasileira contemporânea romper com as clássicas formulações do pensamento social e político brasileiro sobre o tema. Dessa forma, poderemos superar a posição subordinada na geopolítica do conhecimento para que possamos compreender de forma abrangente e descolonizada fenômenos como o autoritarismo que, na modernidade global, não se restringem às fronteiras nacionais.

Marcos Abraão Ribeiro é jornalista, sociólogo, Mestre e Doutor em Sociologia Política pela Universidade Estadual do Norte Fluminense Darcy Ribeiro (UENF), desenvolvendo pesquisas sobre pensamento social e político brasileiro e a aplicação da política de cotas no ensino médio profissionalizante.

凶olamarcos@yahoo.com.br

\footnotetext{
${ }^{8}$ Essa postura pode ser vista no trabalho de Domingues (2013b), que se propõe interpretar a modernidade em perspectiva global a partir da (semi)periferia.

${ }^{9}$ Como afirma Maia (2010), o papel atual do pensamento social brasileiro é construir análises comparativas para observamos o que temos de efetivamente próprio e o que é comum ao Brasil e a outros países do mundo, até mesmo aos países centrais.
} 


\section{Referências}

1. BRANDÃO, Gildo M. Linhagens do pensamento político brasileiro. São Paulo: Hucitec, 2007.

2. CHAUÍ, Marilena. Manifestações ideológicas do autoritarismo brasileiro. Série Escritos de Marilena Chauí, v. 2. Belo Horizonte: Autêntica/Editora Fundação Perseu Abramo, 2013.

3. DAMATTA, Roberto. Carnavais, malandros e heróis: uma interpretação do dilema brasileiro. Rio de Janeiro: Jorge Zahar Editor, 1978.

4. DOMINGUES, José M. O Brasil entre o presente o futuro: conjuntura interna e inserção internacional. Rio de Janeiro: Mauad X, 2013a.

5. DOMINGUES, José M. Modernidade global e civilização contemporânea: para uma renovação da teoria crítica. Belo Horizonte: Editora UFMG, 2013 b.

6. DOMINGUES, José M. Esquerda: crise e futuro. Rio de Janeiro: Maud X, 2017. 7. FAORO, Raymundo. Os donos do poder: formação do patronato político brasileiro. Porto Alegre: Globo, 2008.

8. HOLANDA, Sérgio B. de. Raízes do Brasil. São Paulo: Companhia das Letras, 2010.

9. LYNCH, Christian. Por que pensamento e não teoria? A imaginação políticosocial brasileira e o fantasma da condição periférica (1880-1970). Dados - Revista de Ciências Sociais, v. 56, n. 4, p. 727-767, 2013.

10. LYNCH, Christian. Cartografia do pensamento político brasileiro. Revista Brasileira de Ciência Política, n. 19, p. 75-119, 2016.

11. MACIEL, Fabrício. Ulrich Beck e a crítica ao nacionalismo metodológico. Política e Sociedade, v. 12, n. 25, p. 85-97, 2013.

12. MAIA, João M. O pensamento social brasileiro e a imaginação pós-colonial. Rev. Estudos Políticos, n. 1, p. 64-78, 2010.

13. MIGUEL, Luis F. O colapso da democracia no Brasil. Da Constituição ao golpe de 2016. São Paulo: Expressão Popular/Fundação Rosa Luxemburgo, 2019.

14. PAIM, Antonio. A querela do estatismo. Brasília: Senado Federal, 1998.

15. SANTOS, Wanderley G. A democracia impedida: o Brasil no século XXI. Rio de Janeiro: FGV, 2017.

16. SCHWARCZ, Lilia M. Sobre o autoritarismo brasileiro. São Paulo: Companhia das Letras, 2019.

17. SELL, Carlos E. As duas teorias do patrimonialismo. X Encontro da Associação Brasileira de Ciência Política (ABCP), Anais... Belo Horizonte: ABCP, 2016, p.125. 
18. SCHWARTZMAN, Simon. Bases do autoritarismo brasileiro. 2. ed. Rio de Janeiro: Campus, 1988.

19. SOUZA, Jessé. A radiografia do golpe: entenda como e por que você foi enganado. São Paulo: LeYa, 2016.

20. TAVARES BASTOS, Aureliano C. A província. São Paulo: Companhia Editora Nacional, 1975.

21. TAVARES BASTOS, Aureliano C. Os males do presente e as esperanças do futuro. São Paulo: Companhia Editora Nacional, 1976.

22. TAVOLARO, Sérgio. A tese da singularidade brasileira revisitada: desafios teóricos contemporâneos. Dados - Revista de Ciências Sociais, n. 3, p. 633-673, 2014.

Recebido: 22 nov. 2019.

Aceito: 12 fev. 2020. 